\title{
Mono-ethylhexyl phthalate stimulates prostaglandin secretion in human placental macrophages and THP-1 cells
}

\author{
Lauren M Tetz ${ }^{1,2^{*}}$, David M Aronoff ${ }^{2}$ and Rita Loch-Caruso ${ }^{1}$
}

\begin{abstract}
Background: Diethylhexyl phthalate (DEHP) is widely used as a plasticizer in polyvinyl chloride products. DEHP exposure, which is widespread in the US, increases preterm birth risk; however, the mechanisms driving this relationship are unclear. Because cyclooxygenase-2 (COX-2) dependent prostaglandin synthesis is implicated in preterm birth, we evaluated effects of mono-2-ethylhexyl phthalate (MEHP), the active metabolite of DEHP, on prostaglandin E2 (PGE2) synthesis and COX expression in human placental macrophages (PM). In addition, responses in PM were compared to those in a human macrophage-like cell line, THP-1.
\end{abstract}

Methods: PM and THP-1 cells were treated for 2, 4, 8, or $24 \mathrm{~h}$ with MEHP concentrations ranging from 10 to 180 micromolar. PGE2 concentrations were assessed in culture medium using ELISA, and COX expression was determined by western blot.

Results: Treatment of PM and THP-1 cells with 180 micromolar MEHP for $24 \mathrm{~h}$ significantly increased PGE2 release. Co-treatment of PMs or THP-1 cells with 180 micromolar MEHP and the non-selective COX inhibitor indomethacin reduced MEHP-stimulated PGE2 production. Similarly, co-treatment of PM and THP-1 cells with the COX-2 selective inhibitor NS-398 resulted in a significant decrease in PGE2, suggesting that MEHP-stimulated PGE2 is dependent specifically on increased COX-2 expression. Western blot analysis revealed a significant increase in COX-2 expression in PM and THP-1 cells treated with 180 micromolar MEHP, and no changes in COX-1 expression, supporting the role of COX-2 in MEHP-stimulated PGE2 synthesis.

Conclusions: The findings from this study are the first to demonstrate phthalate-stimulated PGE2 synthesis in PM and warrant future studies into COX-2-dependent prostaglandin synthesis as a mechanism of toxicant-associated preterm birth.

Keywords: Placenta, Macrophage, Phthalates, Cyclooxygenase-2, Prostaglandin E2, Mono-ethylhexyl phthalate

\section{Background}

Preterm birth is a serious health problem, affecting 21 million infants worldwide and half a million per year in the US, and accounting for nearly one-third of all neonatal mortalities [1]. Intrauterine infection is the leading cause of preterm birth, but only represents $40-70 \%$ of total preterm births $[2,3]$. In fact, as many as half of preterm births are attributed to unknown causes [4]. A better

\footnotetext{
*Correspondence: lauren.m.tetz@vanderbilt.edu

'Environmental Health Sciences, University of Michigan, Ann Arbor, Ml 48109, USA

${ }^{2}$ Division of Infectious Diseases, Vanderbilt University Medical Center, Nashville, TN 37232, USA
}

\section{() Biomed Central}

understanding of contributing factors and mechanisms controlling untimely labor is necessary to prevent preterm birth and to improve maternal and fetal health.

A recent report from the Institute of Medicine highlights the importance of further research into factors contributing to preterm birth, including environmental factors such as pollutants [5]. Indeed, exposure during pregnancy to some environmental toxicants, including phthalate esters, increases risk for preterm birth [6-9].

Diethylhexyl phthalate (DEHP) is used widely as a plasticizer in polyvinyl chloride (PVC) consumer products. Because DEHP is not covalently bound to PVC, it 
is released into environmental media, such as water, food, or house dust. Following oral exposure, DEHP is quickly metabolized by gut lipases to its active metabolite, monoethylhexyl phthalate (MEHP), and excreted in the urine. A recent study conducted by the US Centers for Disease Control found measureable levels of MEHP in $80 \%$ of urine samples analyzed, suggesting that exposure to DEHP is widespread in the U.S. population [10].

Previous studies show that women who are more highly exposed to DEHP during pregnancy have an increased risk for preterm birth and other adverse pregnancy outcomes including low birth weight and pregnancy loss [7, 11-14]. Measureable levels of DEHP metabolites, including MEHP, can be found in maternal urine and serum, placental tissue, fetal cord serum, and amniotic fluid, indicating that DEHP metabolites transfer from maternal blood to the fetal compartment [14-17]. Despite the mounting epidemiological evidence demonstrating an association between maternal DEHP exposure and increased risk for preterm birth, the mechanisms underlying these relationships are unclear.

Recent data collected by our laboratory suggest that MEHP stimulates expression in human trophoblast cells of PTGS2, the gene for COX-2 [18], an enzyme that is critical for synthesis of uterotonic prostaglandins, prostaglandin $\mathrm{E}_{2}\left(\mathrm{PGE}_{2}\right)$ and prostaglandin $\mathrm{F}_{2 \alpha}\left(\mathrm{PGF}_{2 \alpha}\right)$. COX-2 dependent prostaglandin synthesis is a critical event for the initiation of human parturition, regulating myometrial contractions and tissue remodeling in the gravid uterus [19]. Inhibition of prostaglandin synthesis following administration of COX-2 inhibitors delays parturition and prevents early labor in rodents, and in vivo exposure to bioactive prostaglandins induces myometrial contractions, cervical ripening and early labor, suggesting that untimely prostaglandin synthesis may drive preterm labor processes [19-22]. In humans, increases in amniotic fluid $\mathrm{PGE}_{2}$ and $\mathrm{PGF}_{2 \alpha}$ correspond with preterm labor and precede spontaneous labor at term [23, 24].

Macrophages within the uteroplacental environment are an important source of bioactive mediators including prostaglandins and cytokines. Placental and decidual macrophages express COX-2 and produce $\mathrm{PGE}_{2}$ in response to LPS or the pro-inflammatory cytokine IL-1 $\beta$ [25-29]. No studies to date have examined the effects of environmental toxicants, such as MEHP, on inducible COX-2 expression or prostaglandin secretion in macrophages from the utero-placental unit. However, several published studies suggest that MEHP influences immune function [30-32]. Therefore, in the current study, we test the hypothesis that MEHP increases prostaglandin secretion through induction of COX-2 expression in human primary placental macrophages (PMs) and in the human macrophage-like cell line, THP-1, to model primary placental and decidual macrophage behavior.

\section{Methods}

This study was reviewed and approved by the Institutional Review Boards (IRBs) at the University of Michigan (\#00035795, approval date 09/25/13) and Vanderbilt University (\#131607, approval date 05/13/14). In compliance with the IRBs, the placental tissues collected for this study would otherwise have been discarded and the investigators did not collect any personal identifiable information or have direct interaction with subjects.

\section{Reagents}

We purchased dimethyl sulfoxide (DMSO), indomethacin, and phorbol-12-myristate-13-acetate (PMA) from Sigma-Aldrich (St. Louis, MO, USA); charcoal-stripped fetal bovine serum (FBS) from HyClone Laboratories (Waltham, MA); RPMI 1640, Dulbecco's Modified Eagle Medium (DMEM), penicillin/streptomycin solution, and phosphate buffered saline (PBS) from Life TechnologiesInvitrogen (Carlsbad, CA); MEHP from Accustandard (New Haven, CT); LPS derived from Salmonella typhimurium from List Biological Laboratory (Campbell, CA); COX-1 and COX-2 monoclonal antibodies, and NS-398, from Cayman Chemical (Ann Arbor, MI); NONIDET P-40 Substitute from Research Products International Corp (Prospect, IL); and protease inhibitor tablets from Roche (Indianapolis, IN).

\section{Third trimester placental tissue acquisition}

Placental tissue was collected from non-laboring women undergoing normal, medically-indicated cesarean section delivery between 37 and 39 weeks of gestation at the University of Michigan Women's Hospital Birth Center or Vanderbilt University Medical Center. A total of 18 placentas were collected for placental macrophage isolation. Tissue samples collected at Vanderbilt University were provided by the Cooperative Human Tissue Network, which is funded by the National Cancer Institute. Exclusion criteria included the following: pre-eclampsia, diabetes, multi-fetal pregnancy, collagen vascular disease, cervical cerclage, immune-compromised conditions, bacterial vaginosis or clinical chorioamnionitis (as noted in the chart or suspected by attending physician), prescription of antibiotics in the past two weeks (with the exception of routine, pre-operative antibiotics), cigarette smoking, third trimester bleeding, major maternal medical conditions (e.g., chronic renal disease, sarcoidosis, hepatitis, HIV), or any condition requiring the tissues to undergo pathological examination.

\section{Placental macrophage isolation and culture}

For placental macrophage isolations, a 30-60 g sample of tissue was excised from the placenta and then transferred to the laboratory in sterile PBS. Isolation of macrophages was performed as described previously [33]. 
Briefly, tissue was washed three times in PBS, digested to a single cell suspension and loaded on a $25 \% / 50 \%$ Percoll gradient to remove cellular debris. Macrophages were isolated from single cell suspensions using MACS Miltenyi CD14 microbeads. Purity of freshly isolated macrophages was $\sim 85 \%$ on average, as assessed by percentage of viable, CD68+ cells, determined by flow cytometry (see Additional file 1: Figure S1, for flow cytometry data). After $24 \mathrm{~h}$ of adherence purification, purity of macrophage cultures was $95 \%$ or above as determined by visual morphological inspection (see Additional file 1: Figure S1 for placental macrophage image). Yields of placental macrophage cells per gram weight of tissue ranged from 2e5-1e6 cells per gram weight of tissue. Cells were seeded at a density of 200,000 cells per well in a polystyrene, 24-well culture plate in RPMI with $1 \%$ antibiotic/ antimycotic solution and $10 \%$ charcoal dextran FBS ( $\mathrm{RPMI}+/+$ ), and then incubated for $24 \mathrm{~h}$ in a humidified atmosphere at $37{ }^{\circ} \mathrm{C}$ and $5 \% \mathrm{CO}_{2}$. Before treatment, cells were visually inspected to verify proper morphology.

\section{THP-1 cell culture}

We used the THP-1 cell line as a model to compare to primary placental macrophages because these cells are easily obtained, are genetically clonal, and represent a potential alternative model to primary cells for macrophage toxicity testing in cases where human placental tissues are difficult to obtain. The human monocytic leukemia cell line THP-1 was obtained from the American Type Culture Collection (ATCC, TIB-202; Manassas, VA, USA) and cultured as described previously [34]. THP-1 cells were used in this study to model placental and decidual macrophage behavior, as we have demonstrated previously [35]. THP-1 cells were seeded at a density of 200,000 cells per well in a 24-well plate, cultured overnight, and then differentiated into adherent, macrophage-like cells by culturing with $100 \mathrm{nM}$ PMA in $\mathrm{RPMI}+/+$ for $24 \mathrm{~h}$ at $37{ }^{\circ} \mathrm{C}$ and $5 \% \mathrm{CO}_{2}$. After differentiation and before treatment, cells were washed once with culture medium to remove residual PMA. PMAtreated THP-1 cells were used for all THP-1 cell experiments described in this study. For the indomethacin studies, THP-1 cells were seeded at a density of 200,000 cells per well in a 96-well plate and cultured for $24 \mathrm{~h}$ following PMA treatment in RPMI $+/+$, before co-treating with indomethacin and MEHP.

\section{Placental macrophage and THP-1 cell treatment}

Primary PMs and THP-1 cells were treated with medium alone, $0.05 \%$ DMSO (solvent control), or 10, 45, 90 or $180 \mu \mathrm{M}$ MEHP in triplicate in RPMI 1640 medium (with L-glutamine without phenol red, supplemented with $100 \mathrm{U} / \mathrm{mL}$ penicillin and $100 \mu \mathrm{g} / \mathrm{mL}$ streptomycin) for $2,4,8$, or $24 \mathrm{~h}$ in a humidified atmosphere at $37{ }^{\circ} \mathrm{C}$ and $5 \% \mathrm{CO}_{2}$. For PM experiments, experiments were repeated a minimum of 3 times, each time using cells isolated from one woman's placental tissue, with treatments balanced across subjects. For THP1 experiments, experiments were repeated a minimum of three times on different days. For indomethacin inhibitor experiments, cells were treated with solvent control or $180 \mu \mathrm{M}$ MEHP and co-treated with either 1 or $10 \mu \mathrm{M}$ indomethacin, a non-selective COX inhibitor, for $24 \mathrm{~h}$. For COX-2 selective inhibition experiments, cells were pretreated with $1 \mu \mathrm{M} \mathrm{NS}-398$ for $30 \mathrm{~min}$, and then treated for $24 \mathrm{~h}$ with solvent control or $180 \mu \mathrm{M}$ MEHP with or without $1 \mu \mathrm{M}$ NS-398. Effective inhibitor concentrations were identified based on preliminary concentration response curves in THP-1 cells, using $500 \mathrm{ng} / \mathrm{mL}$ LPS as an inducer of COX-2 (data not shown). Concentrations of MEHP used for the current study were sub-cytotoxic, as determined by a lactate dehydrogenase assay on treatment medium from PM and THP- 1 cells treated with $0,45,90$, and $180 \mu \mathrm{M}$ MEHP for $24 \mathrm{~h}$ (data not shown).

\section{Prostaglandin quantification}

We measured MEHP-stimulated prostaglandin secretion in human primary PM cells and THP-1 cells in culture. $\mathrm{PGE}_{2}$ and $\mathrm{PGF}_{2 \alpha}$ concentrations in the culture medium were quantified with enzyme immunoassay (EIA) following the manufacturer's recommended protocol (Cayman Chemical, Ann Arbor, MI, USA).

\section{Western immunoblot for COX-1 and COX-2 protein expression}

THP- 1 cells were seeded at a density of $5 \mathrm{e} 6$ cells per dish in a $60-\mathrm{mm}$ polystyrene culture dish and PMs were seeded at a density of $10 \mathrm{e} 6$ cells per well in a 6-well polystyrene culture plate. Following $24 \mathrm{~h}$ incubation, cells were treated for $8 \mathrm{~h}$ with solvent control $(0.05 \%$ DMSO), $180 \mu \mathrm{M}$ MEHP, or $500 \mathrm{ng} / \mathrm{mL}$ LPS. Following treatment, cells were lysed with ice-cold lysis buffer (0.5\% NONIDET P-40 Substitute, $250 \mathrm{mM} \mathrm{NaCl}$, $50 \mathrm{mM}$ Tris- $\mathrm{HCl}$, with $2 \mathrm{X}$ protease inhibitor tablets). Protein was separated on a $10 \%$ polyacrylamide gel and then transferred to a PVDF membrane. All samples were run alongside $\mathrm{COX}-1$ and $\mathrm{COX}-2$ positive control lysates (human COX-2 control lysates were obtained from Cayman chemical and COX-1 control lysates were a gift from Dr. William L. Smith, University of Michigan). Membranes were probed for COX-1 (antihuman COX-1 mouse monoclonal antibody; $5 \mu \mathrm{g} / \mathrm{mL}$ ), COX-2 (anti-human COX-2 mouse monoclonal antibody; $0.5 \mu \mathrm{g} / \mathrm{mL}$ ) and $\alpha$-tubulin (anti- $\alpha$-tubulin mouse monoclonal antibody; 1:40,000) or GAPDH (anti-GAPDH rabbit monoclonal antibody; 1:1000). 


\section{Statistical analysis}

Data for each cytokine were expressed as $\mathrm{pg} / \mathrm{ml}$ and analyzed by ANOVA to test for treatment effect, followed by Tukey post hoc pairwise comparison of means when ANOVAs were statistically significant. For experiments with replicates within an experimental day, mixed model ANOVA was used with treatment as the fixed variable and experiment day as the random variable. Data are expressed as the mean \pm SE of 3 different experimental days for THP-1 cells or 3-4 women, depending on the experiment, for placental macrophages.

\section{Results}

\section{MEHP-stimulated prostaglandin synthesis in placental} macrophage cultures

Treatment of primary PMs with $180 \mu \mathrm{M}$ MEHP but not 10 , 45, or $90 \mu \mathrm{M}$ MEHP for $24 \mathrm{~h}$ significantly increased $\mathrm{PGE}_{2}$ release by 1.7-fold (Fig. 1a,b). Furthermore, treatment with 90 or $180 \mu \mathrm{M}$ MEHP significantly stimulated $\mathrm{PGF}_{2 \alpha}$ release from PM cells by approximately 1.5 and 1.8-fold, respectively (Fig. 1c). We observed no statistically significant effect of $180 \mu \mathrm{M}$ MEHP on $\mathrm{PGE}_{2}$ concentrations after 2,4 , or $8 \mathrm{~h}$ compared to solvent controls (Fig. 1a). However, there was a trend suggestive of increased $\mathrm{PGE}_{2}$ at all time-points measured. The effects of $180 \mu \mathrm{M}$ MEHP treatment on $\mathrm{PGE}_{2}$ synthesis were reproducible in THP-1 cells used to model PM behavior (Fig. 1f,g).

\section{Effects of COX inhibitors on MEHP-stimulated PGE 2 release}

Co-treatment with $1 \mu \mathrm{M}$ indomethacin, a non-selective COX inhibitor, significantly decreased MEHP-stimulated $\mathrm{PGE}_{2}$ release in PMs and THP-1 cells by $77 \%$ and $60 \%$, respectively, compared to MEHP alone, confirming COX-dependent $\mathrm{PGE}_{2}$ synthesis with MEHP stimulation (Fig. 1d,f). Furthermore, co-treatment of PMs or THP-1 cells with the COX-2 selective inhibitor NS-398 resulted in significant decreases in $\mathrm{PGE}_{2}$ concentrations of $70 \%$ and $57 \%$, respectively, compared with MEHP alone, suggesting that MEHP-stimulated $\mathrm{PGE}_{2}$ synthesis is dependent on COX-2 activity, specifically.

\section{MEHP effects on COX-1 and COX-2 protein expression in placental macrophage and THP-1 cells}

Western blot densitometric analysis revealed a significant increase in COX-2 protein expression of approximately 2-fold in PMs treated with $180 \mu \mathrm{M}$ MEHP (Fig. 2a,c) but no significant changes in COX-1 expression (Fig. 2b,c), supporting the role of COX-2 in MEHP-stimulated $\mathrm{PGE}_{2}$ synthesis. MEHP induction of COX-2 was also observed in THP-1 cells (Fig. 3). Furthermore, $180 \mu \mathrm{M}$ MEHP induced COX-2 expression at levels comparable to those observed with a potent pro-inflammatory stimulus, lipopolysaccharide (LPS; Figs. 2 and 3).

\section{Discussion}

Exposure during pregnancy to the common environmental contaminant DEHP has been associated in epidemiologic studies with increased risk for preterm birth $[7,11]$. Because immune cells can be important sources of uterotonic prostaglandins [36], the objective of the current study was to determine the influence of MEHP, a principle bioactive metabolite of DEHP, on prostaglandin synthesis in primary human PMs. Our results demonstrate that MEHP-stimulated synthesis of uterotonic prostaglandins is dependent on the activity of inducible COX-2 enzyme in both PMs and THP-1 cells. Furthermore, MEHP induced COX-2 expression at levels comparable to those observed with a potent proinflammatory stimulus, lipopolysaccharide. We observed significant effects with MEHP concentrations ranging from 90 to $180 \mu \mathrm{M}$. These concentrations are within one order of magnitude of average MEHP concentrations reported by Lin et al. [37] in human umbilical cord serum $(35.7 \mu \mathrm{M})$ and human maternal serum $(42.6 \mu \mathrm{M})$, but are higher than concentrations reported by Latini et al. [11] in their study of MEHP in umbilical cord serum (average of $1.8 \pm 2.2 \mu \mathrm{M}$, range of $0-10.6 \mu \mathrm{M}$ ). To our knowledge, this study represents the first to examine effects of a reproductive toxicant on PMs. These findings support MEHP-stimulated prostaglandin synthesis and induction of COX-2 enzyme in PMs as a potential mechanism for MEHP-associated preterm birth. Moreover, the similar responses we observed with the human monocyte cell line THP-1 suggest that MEHP may have a general immunomodulatory effect on prostaglandin synthesis, which may have implications for other disease outcomes as well.

The findings from the present study are concordant with our previous findings demonstrating an increase in PTGS2 mRNA expression in placental trophoblast cells with 90 and $180 \mu \mathrm{M}$ MEHP [18]. In addition, MEHP exposure has previously been shown to induce expression of COX-2 in immortalized murine liver cells, murine spermatocytes, and rat alveolar macrophages at concentrations ranging from 200 to $1000 \mu \mathrm{M}$ MEHP [38-40]. Notably, the present study includes the lowest effective concentration yet reported for MEHP effects on COX-2 expression in an immune cell, to the best of our knowledge.

Contrary to the findings from the present study, $\mathrm{Xu}$ et al. observed decreased COX-2 expression in the junctional zone of placenta from pregnant rats dosed with 750 or $1500 \mathrm{mg} / \mathrm{kg}$ DEHP daily from gestational day 0 to 19 [41]. The discrepancy between the current study and the findings of $\mathrm{Xu}$ et al. may be explained by 


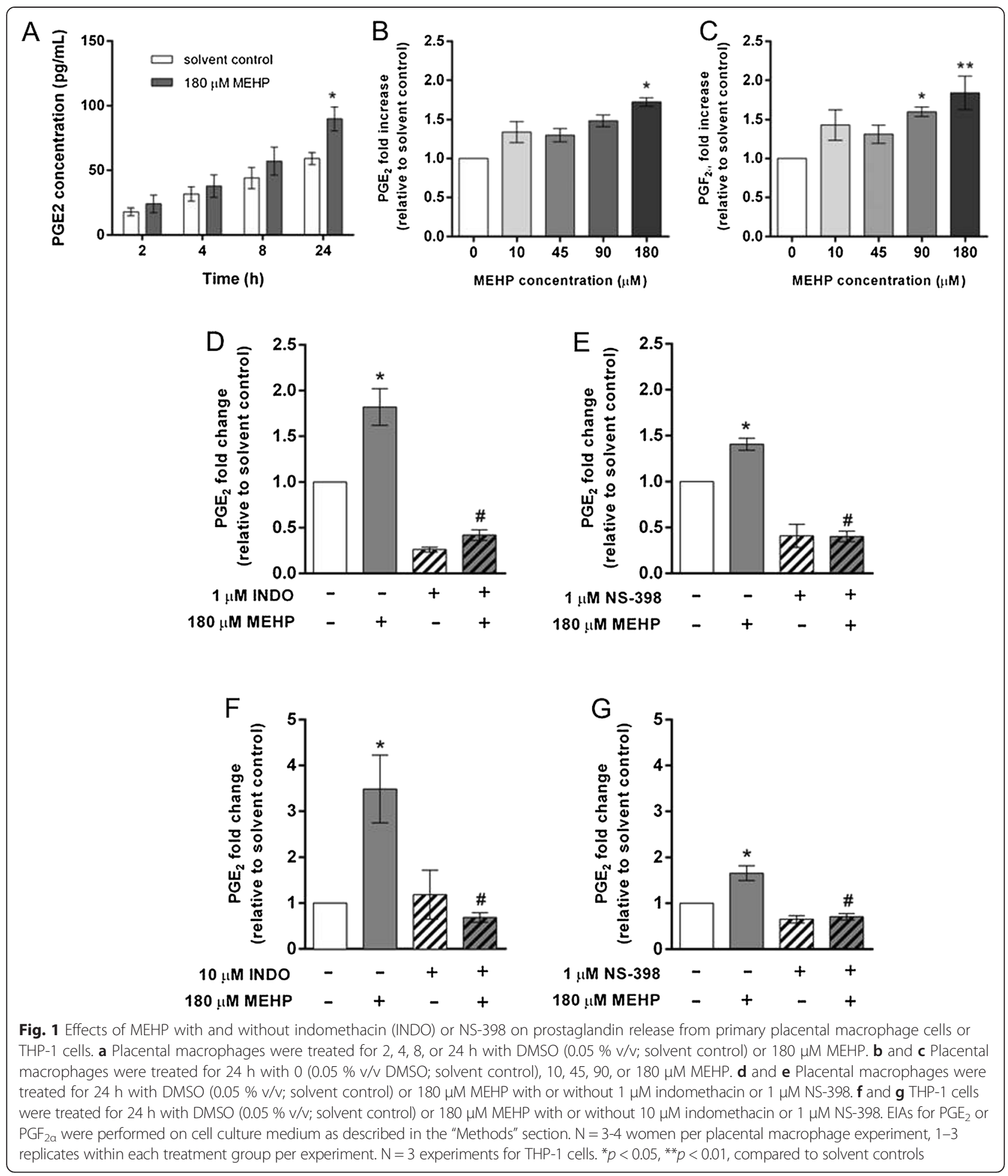

differences in in vitro culture conditions and in vivo exposure, differences in responses to MEHP between species, differences in cellular response due to chronic in vivo, vs. acute in vitro exposure, or differences in MEHP responses of whole placental tissue compared to isolated placental macrophage cells. Furthermore, although the lowest effective dose of DEHP given in the Xu et al. study resulted in a serum MEHP concentration of $234 \mu \mathrm{M}$, similar to the highest concentration used in the current study, a significant amount of DEHP remained in the rat serum 


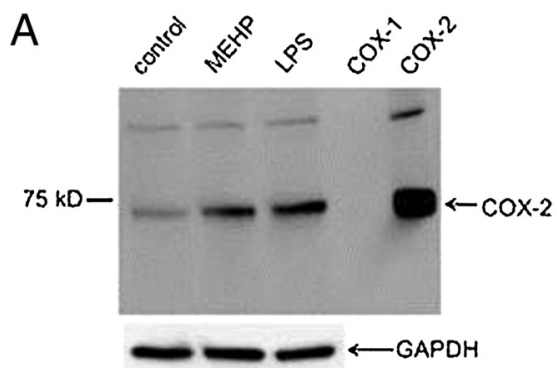

C

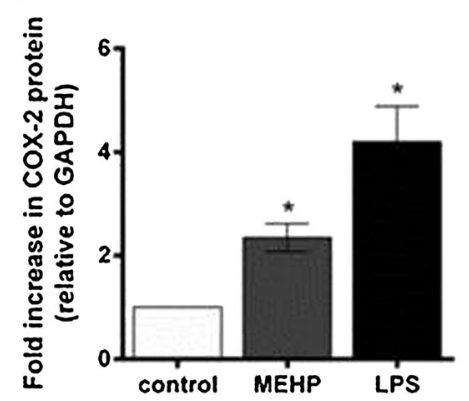

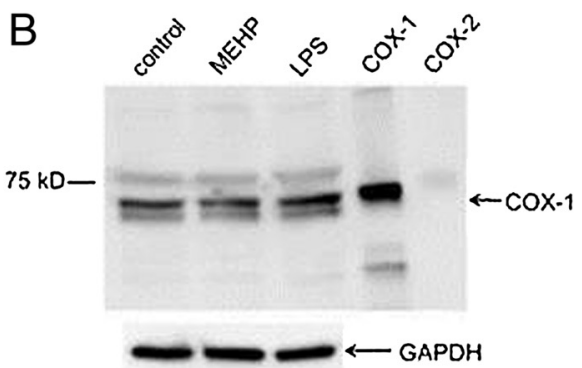

D

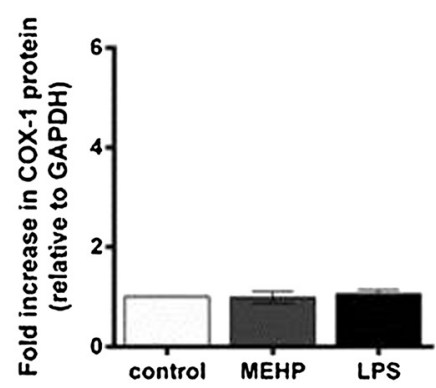

Fig. 2 MEHP effects on COX-1 and COX-2 protein expression in placental macrophages. Western blot and densitometry analysis of COX-2 (a and c) and COX-1 (b and $\mathbf{d})$ in placental macrophages treated for $8 \mathrm{~h}$ with DMSO $(0.05 \% \mathrm{v} / \mathrm{V}$; solvent control), $180 \mu \mathrm{M} \mathrm{MEHP} \mathrm{or} 500 \mathrm{ng} / \mathrm{mL}$ LPS. Western blot and densitometry analysis was performed on placental macrophage lysates as described in the "Methods" section. All samples were run alongside COX-1 and COX-2 positive control lysates, seen on the far right of the gel. $\mathrm{N}=3$ women. ${ }^{*} p<0.05$, compared to solvent controls

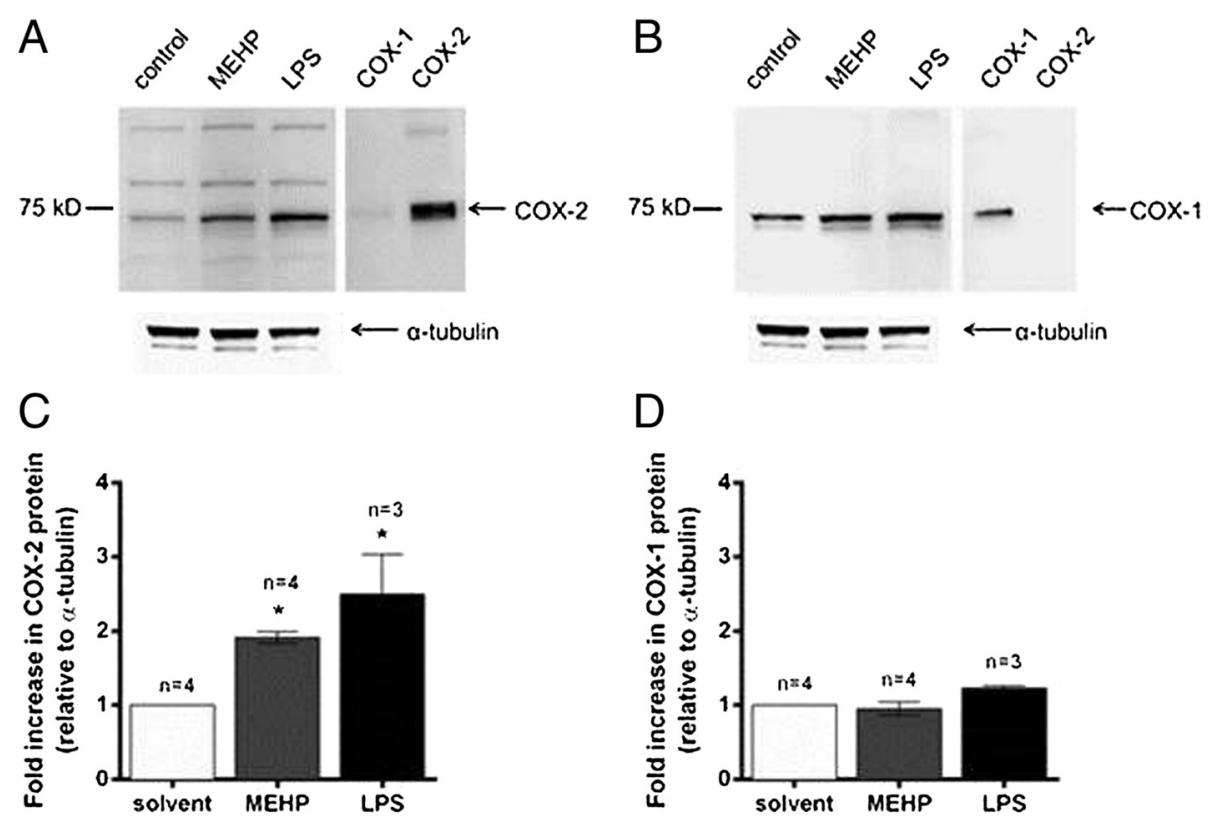

Fig. 3 MEHP effects on COX-1 and COX-2 protein expression in THP-1 cells. Western blot and densitometry analysis of COX-2 (a and c) and COX-1 (b and $\mathbf{d}$ ) in THP-1 cells treated for $8 \mathrm{~h}$ with DMSO (0.05\% v/v; solvent control), $180 \mu \mathrm{M}$ MEHP or $500 \mathrm{ng} / \mathrm{mL}$ LPS. Western blot analysis was performed on THP-1 cell lysates as described in the "Methods" section. All samples were run alongside COX-1 and COX-2 positive control lysates, seen on the far right of the gel. $N=3-4$ experiments. ${ }^{*} p<0.05$, compared to solvent controls 
following exposure. Therefore, the observed differences could also be due to the additional presence of DEHP in the serum of exposed rats.

The investigations presented here utilized both primary placental macrophages and the human macrophage-like THP-1 cell line. As noted in previous studies, THP-1 cells respond similarly compared to primary placental and decidual macrophages in their response to bacterial infection [35]. However, no studies to date have compared THP-1 cells to primary placental macrophages in their ability to respond to reproductive toxicants. Our data are the first to demonstrate that THP-1 cells respond similarly to primary placental macrophages in their secretion of prostaglandins and induction of COX expression in response to MEHP treatment. Thus, THP-1 cells may represent a facile model of placental macrophages for investigating the influence of environmental toxicants on macrophage function.

The mechanism of MEHP-stimulated prostaglandin synthesis in placental cells remains to be elucidated; however, recent evidence suggests that PPAR may be important for MEHP modulation of inflammatory responses [31, 32]. DEHP and MEHP are putative PPAR activators, and several studies show that MEHP-mediated toxicity is dependent on PPAR in a variety of tissue and cell types [31, 42]. Furthermore, because PPAR is an important regulator of inflammatory responses in macrophages, future studies could examine PPAR activation as a potential mechanism for MEHP-stimulated prostaglandin synthesis in primary PMs [43].

In addition to effects on labor processes, MEHPstimulation of $\mathrm{PGE}_{2}$ synthesis may have implications for innate immune function in the female reproductive tract. Previous findings from our group suggest that exaggerated levels of $\mathrm{PGE}_{2}$ suppress immune responses against intrauterine Group A Streptococcus infection [35]. Because intrauterine infection is an important causal factor for preterm labor, future studies could examine the influence of MEHP-stimulated $\mathrm{PGE}_{2}$ synthesis on the progression of intrauterine infections.

\section{Conclusions}

The findings from the current study demonstrate COX2-dependent stimulation of $\mathrm{PGE}_{2}$ by MEHP in primary human PMs and THP-1 cells, suggesting that PMs may be an important target of MEHP toxicity. Because COX-2 dependent prostaglandin synthesis is implicated in preterm labor processes, these findings may represent a potential mechanism by which MEHP contributes to risk for preterm birth. Furthermore, these findings support future epidemiological research examining the influence of DEHP exposure on prostaglandin synthesis in the uteroplacental unit.

\section{Additional file}

Additional file 1: Figure S1. Placental Macrophage Culture Purity. In this file, we have included the flow cytometry data from freshly isolated macrophages showing $\mathrm{CD}^{+} 8^{+}$cell percentages and an image of the placental macrophage cultures after $24 \mathrm{~h}$ of adherence purification.

\section{Competing interests}

The authors declare that they have no competing interests.

\section{Authors' contributions}

LMT, DMA, RLC conceived and designed the experiments. LMT performed the experiments. LMT and RLC performed data analysis. LMT and RLC drafted the manuscript. All authors read and approved the final manuscript.

\section{Acknowledgments}

We thank Dr. Mark Chames at University of Michigan Women's Birth Center and the Cooperative Human Tissue Network for assistance in collection of placental specimens. This work was supported by grants from the National Institute of Environmental Health Sciences (NIEHS), National Institutes of Health (NIH) to R.L.C. for projects in the Superfund Research Program PROTECT Center (P42 ES017198); and a NRSA Institutional Training Grant predoctoral fellowship to L.M.T. (T32 ES007062).

Disclaimer: This manuscript does not reflect policies of the National Institute of Environmental Health Sciences (NIEHS) of the National Institutes of Health (NIH).

Received: 10 February 2015 Accepted: 13 May 2015

Published online: 03 June 2015

\section{References}

1. Callaghan WM, MacDorman MF, Rasmussen SA, Qin C, Lackritz EM. The contribution of preterm birth to infant mortality rates in the United States. Pediatrics. 2006;118(4):1566-73. doi:10.1542/peds.2006-0860.

2. Goldenberg RL, Rouse DJ. Prevention of premature birth. N Engl J Med. 1998;339(5):313-20. doi:10.1056/NEJM199807303390506.

3. Romero R, Chaiworapongsa T, Espinoza J. Micronutrients and intrauterine infection, preterm birth and the fetal inflammatory response syndrome. J Nutr. 2003;133(5):1668S-73.

4. Hamilton BE, Martin JA, Ventura SJ, Sutton PD, Menacker F. Births: preliminary data for 2004. In: NCFH, editor. Statistics. Hyattsville, MD: National Vital Statistics Reports; 2005.

5. Behrman RE, Butler AS. Preterm birth: causes, consequences, and prevention. Washington, DC: National Academies Press; 2007.

6. Longnecker MP, Klebanoff MA, Zhou H, Brock JW. Association between maternal serum concentration of the DDT metabolite DDE and preterm and small-for-gestational-age babies at birth. Lancet. 2001;358(9276):110-4. doi:10.1016/s0140-6736(01)05329-6.

7. Ferguson KK, McElrath TF, Meeker JD. Environmental phthalate exposure and preterm birth. JAMA Pediatr. 2014;168(1):61-7. doi:10.1001/jamapediatrics.2013.3699.

8. Luo YJ, Wen XZ, Ding P, He YH, Xie CB, Liu T, et al. Interaction between maternal passive smoking during pregnancy and CYP1A1 and GSTs polymorphisms on spontaneous preterm delivery. PLoS One. 2012;7(11):e49155. doi:10.1371/journal.pone.0049155.

9. van den Hooven EH, Pierik FH, de Kluizenaar Y, Willemsen SP, Hofman A, van Ratingen SW, et al. Air pollution exposure during pregnancy, ultrasound measures of fetal growth, and adverse birth outcomes: a prospective cohort study. Environ Health Perspect. 2012;120(1):150-6. doi:10.1289/ehp.1003316.

10. Ferguson KK, Loch-Caruso R, Meeker JD. Urinary phthalate metabolites in relation to biomarkers of inflammation and oxidative stress: NHANES 1999-2006. Environ Res. $2011 ; 111(5): 718-26$. doi:10.1016/j.envres.2011.02.002.

11. Latini G, De Felice C, Presta G, Del Vecchio A, Paris I, Ruggieri F, et al. In utero exposure to di-(2-ethylhexyl) phthalate and duration of human pregnancy. Environ Health Perspect. 2003;111(14):1783-5.

12. Meeker JD, Hu H, Cantonwine DE, Lamadrid-Figueroa H, Calafat AM, Ettinger AS, et al. Urinary phthalate metabolites in relation to preterm birth in Mexico City. Environ Health Perspect. 2009;117(10):1587-92. doi:10.1289/ehp.0800522.

13. Toft $G$, Jonsson BA, Lindh $\mathrm{CH}$, Jensen $\mathrm{TK}$, Hjollund $\mathrm{NH}$, Vested $\mathrm{A}$, et al. Association between pregnancy loss and urinary phthalate levels around 
the time of conception. Environ Health Perspect. 2012;120(3):458-63. doi:10.1289/ehp.1103552.

14. Zhang $Y$, Lin L, Cao Y, Chen B, Zheng L, Ge RS. Phthalate levels and low birth weight: a nested case-control study of Chinese newborns. J Pediatr. 2009;155(4):500-4. doi:10.1016/.j.jpeds.2009.04.007.

15. Mose T, Mortensen GK, Hedegaard M, Knudsen LE. Phthalate monoesters in perfusate from a dual placenta perfusion system, the placenta tissue and umbilical cord blood. Reprod Toxicol. 2007;23(1):83-91. doi:10.1016/j.reprotox.2006.08.006.

16. Wittassek M, Angerer J, Kolossa-Gehring M, Schafer SD, Klockenbusch W, Dobler L, et al. Fetal exposure to phthalates-a pilot study. Int I Hyg Environ Health. 2009;212(5):492-8. doi:10.1016/j.ijheh.2009.04.001.

17. Silva MJ, Reidy JA, Herbert AR, Preau Jr JL, Needham LL, Calafat AM. Detection of phthalate metabolites in human amniotic fluid. Bull Environ Contam Toxicol. 2004;72(6):1226-31.

18. Tetz LM, Cheng AA, Korte CS, Giese RW, Wang P, Harris C, et al. Mono-2ethylhexyl phthalate induces oxidative stress responses in human placental cells in vitro. Toxicol Appl Pharmacol. 2013;268(1):47-54. doi:10.1016/j.taap.2013.01.020

19. Timmons BC, Reese J, Socrate S, Ehinger N, Paria BC, Milne GL, et al. Prostaglandins are essential for cervical ripening in LPS-mediated preterm birth but not term or antiprogestin-driven preterm ripening. Endocrinology. 2014;155(1):287-98. doi:10.1210/en.2013-1304.

20. Wikland $M$, Lindblom B, Wiqvist N. Myometrial response to prostaglandins during labor. Gynecol Obstet Invest. 1984;17(3):131-8.

21. Lee PR, Kim SR, Jung BK, Kim KR, Chung JY, Won HS, et al. Therapeutic effect of cyclo-oxygenase inhibitors with different isoform selectivity in lipopolysaccharide-induced preterm birth in mice. Am J Obstet Gynecol. 2003;189(1):261-6.

22. Gross G, Imamura T, Vogt SK, Wozniak DF, Nelson DM, Sadovsky Y, et al. Inhibition of cyclooxygenase-2 prevents inflammation-mediated preterm labor in the mouse. Am J Physiol Regul Integr Comp Physiol. 2000;278(6):R1415-23.

23. Lee SE, Romero R, Park IS, Seong HS, Park CW, Yoon BH. Amniotic fluid prostaglandin concentrations increase before the onset of spontaneous labor at term. J Matern Fetal Neonatal Med. 2008;21(2):89-94. doi:10.1080/14767050701830514.

24. Mazor M, Wiznitzer A, Maymon E, Leiberman JR, Cohen A. Changes in amniotic fluid concentrations of prostaglandins E2 and F2 alpha in women with preterm labor. Isr J Med Sci. 1990;26(8):425-8.

25. Wetzka B, Clark DE, Charnock-Jones DS, Zahradnik HP, Smith SK. PGE2 and TXA2 production by isolated macrophages from human placenta. Adv Exp Med Biol. 1997;433:403-6.

26. Hanna N, Bonifacio L, Weinberger B, Reddy P, Murphy S, Romero R, et al. Evidence for interleukin-10-mediated inhibition of cyclo- oxygenase-2 expression and prostaglandin production in preterm human placenta. Am J Reprod Immunol. 2006;55(1):19-27. doi:10.1111/j.1600-0897.2005.00342.x.

27. Wetzka B, Nusing R, Charnock-Jones DS, Schafer W, Zahradnik HP, Smith SK. Cyclooxygenase- 1 and -2 in human placenta and placental bed after normal and pre-eclamptic pregnancies. Hum Reprod. 1997;12(10):2313-20. doi:10.1093/humrep/12.10.2313

28. Mizuno M, Aoki K, Kimbara T. Functions of macrophages in human decidual tissue in early pregnancy. Am J Reprod Immunol. 1994;31(4):180-8.

29. Adeleye $T A$, Elder MG, Sullivan MH. Preparation of a population of macrophages from human third trimester decidua. Hum Reprod. 1996;11(2):451-6

30. Jepsen KF, Abildtrup A, Larsen ST. Monophthalates promote IL-6 and IL-8 production in the human epithelial cell line A549. Toxicol in Vitro. 2004;18(3):265-9. doi:10.1016/j.tiv.2003.09.008.

31. Bolling AK, Ovrevik J, Samuelsen JT, Holme JA, Rakkestad KE, Mathisen GH, et al. Mono-2-ethylhexylphthalate (MEHP) induces TNF-alpha release and macrophage differentiation through different signalling pathways in RAW264.7 cells. Toxicol Lett. 2012;209(1):43-50. doi:10.1016/j.toxlet.2011.11.016.

32. Vetrano AM, Laskin DL, Archer F, Syed K, Gray JP, Laskin JD, et al. Inflammatory effects of phthalates in neonatal neutrophils. Pediatr Res. 2010;68(2):134-9. doi:10.1203/00006450-201011001-00260.

33. Soares EM, Mason KL, Rogers LM, Serezani CH, Faccioli LH, Aronoff DM. Leukotriene B4 enhances innate immune defense against the puerperal sepsis agent Streptococcus pyogenes. J Immunol. 2013;190(4):1614-22. doi:10.4049/jimmunol.1202932.
34. Rogers LM, Thelen T, Fordyce K, Bourdonnay E, Lewis C, Yu H, et al. EP4 and EP2 receptor activation of protein kinase $A$ by prostaglandin E2 impairs macrophage phagocytosis of Clostridium sordellii. Am J Reprod Immunol. 2014;71(1):34-43. doi:10.1111/aji.12153.

35. Mason KL, Rogers LM, Soares EM, Bani-Hashemi T, Erb Downward J, Agnew $D$, et al. Intrauterine group A streptococcal infections are exacerbated by prostaglandin E2. J Immunol. 2013;191(5):2457-65. doi:10.4049/jimmunol.1300786.

36. Nagamatsu T, Schust DJ. The immunomodulatory roles of macrophages at the maternal-fetal interface. Reprod Sci. 2010;17(3):209-18. doi:10.1177/1933719109349962

37. Lin $L$, Zheng $L X$, Gu YP, Wang JY, Zhang YH, Song WM. Levels of environmental endocrine disruptors in umbilical cord blood and maternal blood of low-birth-weight infants. Zhonghua Yu Fang Yi Xue Za Zhi. 2008:42(3):177-80.

38. Ledwith BJ, Pauley CJ, Wagner LK, Rokos CL, Alberts DW, Manam S. Induction of cyclooxygenase-2 expression by peroxisome proliferators and non-tetradecanoylphorbol 12,13-myristate-type tumor promoters in immortalized mouse liver cells. J Biol Chem. 1997;272(6):3707-14.

39. Onorato TM, Brown PW, Morris PL. Mono-(2-ethylhexyl) phthalate increases spermatocyte mitochondrial peroxiredoxin 3 and cyclooxygenase 2. J Androl. 2008;29(3):293-303. doi:10.2164/jandrol.107.003335.

40. Rakkestad KE, Holme JA, Paulsen RE, Schwarze PE, Becher R. Mono (2-ethylhexyl) phthalate induces both pro- and anti-inflammatory responses in rat alveolar macrophages through crosstalk between p38, the lipoxygenase pathway and PPARalpha. Inhal Toxicol. 2010;22(2):140-50. doi:10.3109/08958370903019885.

41. Xu Y, Agrawal S, Cook TJ, Knipp GT. Maternal di-(2-ethylhexyl)-phthalate exposure influences essential fatty acid homeostasis in rat placenta. Placenta. 2008;29(11):962-9. doi:10.1016/j.placenta.2008.08.011.

42. Desvergne B, Feige JN, Casals-Casas C. PPAR-mediated activity of phthalates: a link to the obesity epidemic? Mol Cell Endocrinol. 2009;304(1-2):43-8. doi:10.1016/.mce.2009.02.017

43. Odegaard Jl, Ricardo-Gonzalez RR, Goforth MH, Morel CR, Subramanian V, Mukundan L, et al. Macrophage-specific PPARgamma controls alternative activation and improves insulin resistance. Nature. 2007;447(7148):1116-20. doi:10.1038/nature05894.

\section{Submit your next manuscript to BioMed Central and take full advantage of:}

- Convenient online submission

- Thorough peer review

- No space constraints or color figure charges

- Immediate publication on acceptance

- Inclusion in PubMed, CAS, Scopus and Google Scholar

- Research which is freely available for redistribution 